\title{
Economic viability of distributed energy resources relative to substation and feeder facilities expansion
}

\begin{abstract}
Distributed energy resources have numerous benefits, of which is transmission network upgrade deferral. This application is particularly important where there are constraints in upgrading of the existing or construction of new generation units and transmission circuits. This paper presents a cost comparison of the central plant option and DG in meeting additional load demand. The economic analysis for a twenty-year planning horizon is carried out in this study using present worth factor. The results obtained with a 30-bus test radial distribution network using MATPOWER show the economic viability of DG when compared with upgrading the existing substation and feeder facilities, especially when incremental load is considered.
\end{abstract}

Keyword: Central generation; Distributed energy resources; Distributed generation; Power loss; Worth factor 